See discussions, stats, and author profiles for this publication at: http://www.researchgate.net/publication/231821291

\title{
Experiences with Stochastic Algorithms for a class of Constrained Global Optimisation Problems
}

ARTICLE in RAIRO - OPERATIONS RESEARCH • MARCH 2000

Impact Factor: 0.41 $\cdot$ DOI: 10.1051/ro:2000110

CITATIONS

4 AUTHORS, INCLUDING:

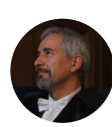

Abdel Salhi

University of Essex

73 PUBLICATIONS 252 CITATIONS

SEE PROFILE
READS

-G. Proll

University of Leeds

46 PUBLICATIONS 389 CITATIONS

SEE PROFILE 


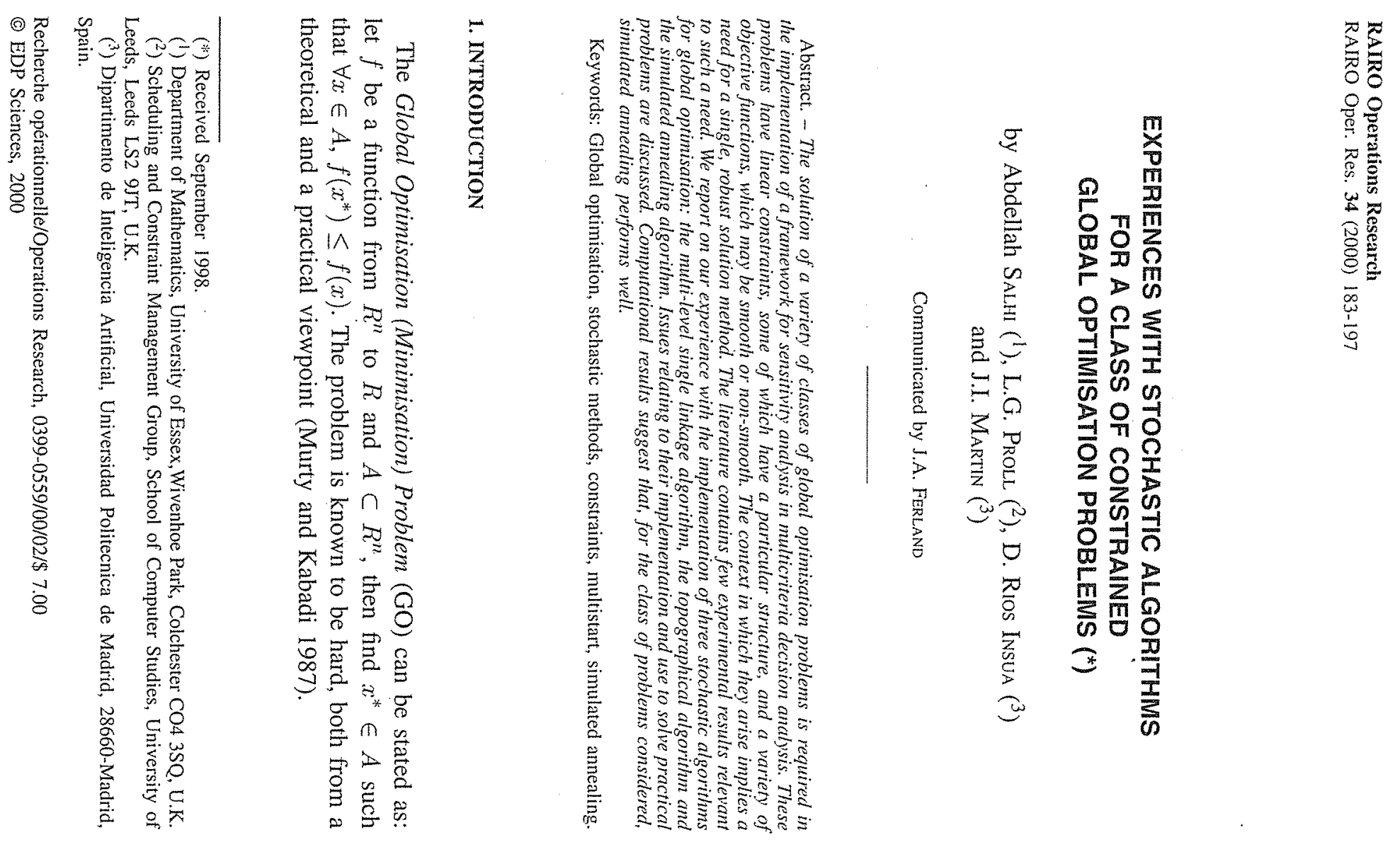



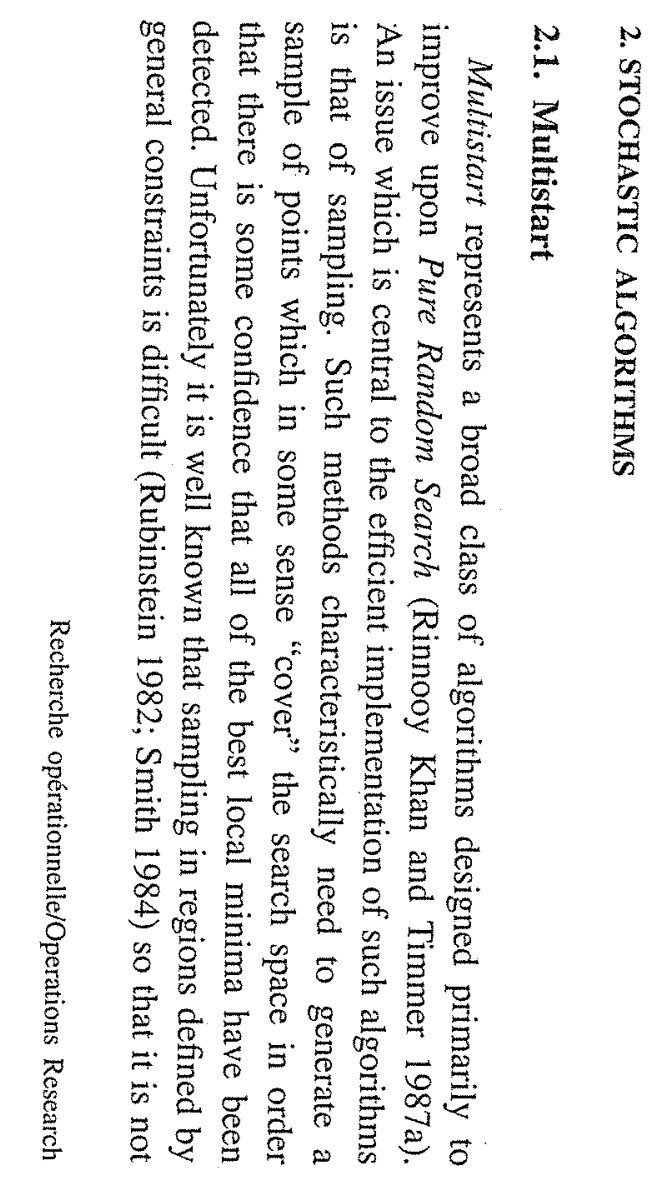

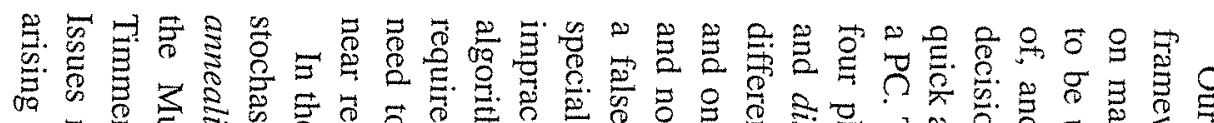
$\bar{\alpha}$

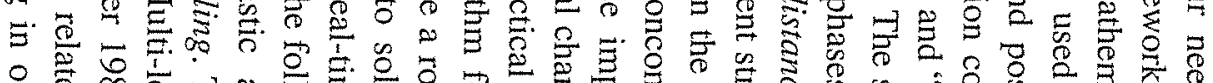

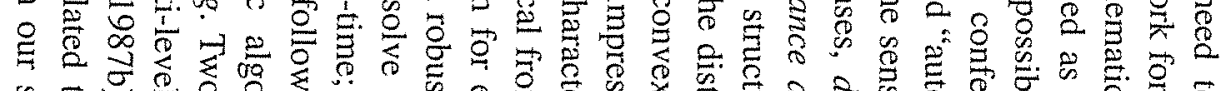

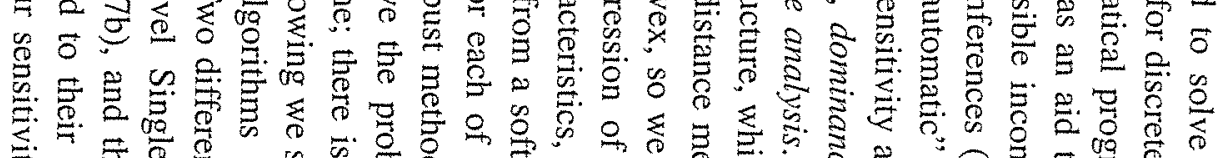

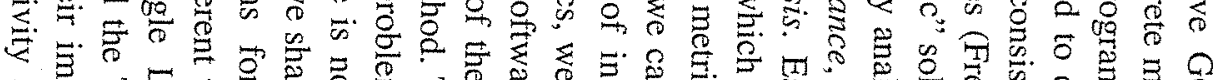

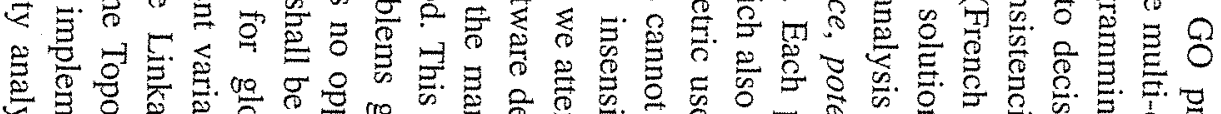

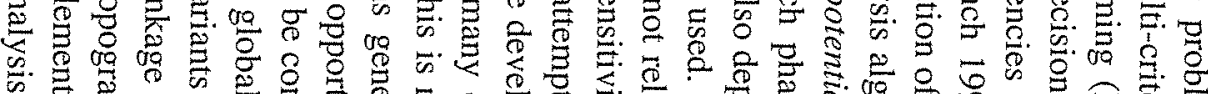

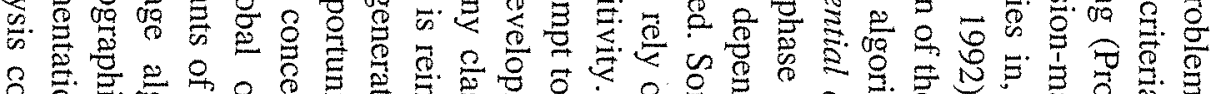

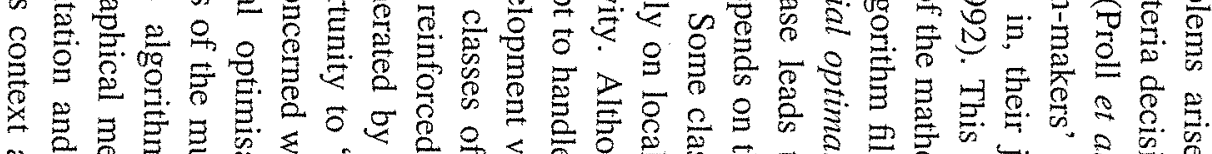

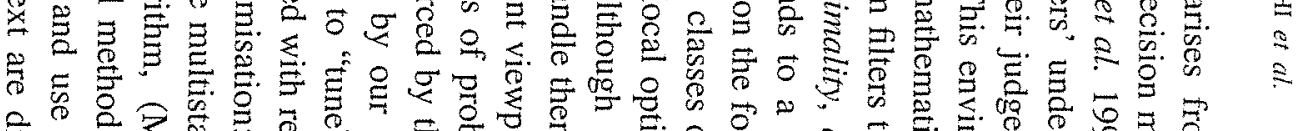
家

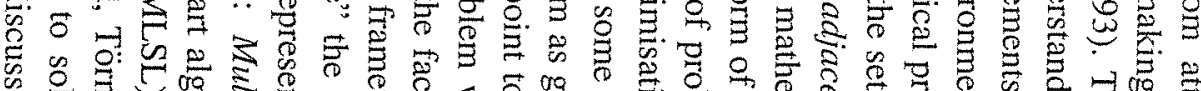

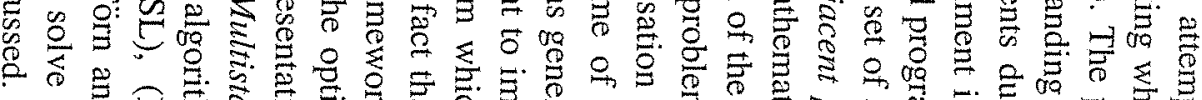

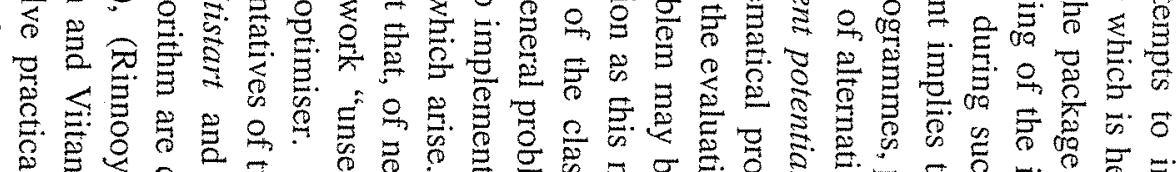

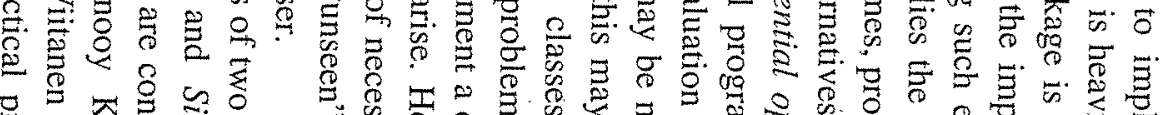

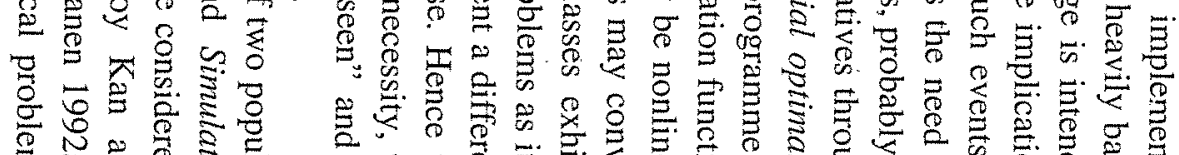

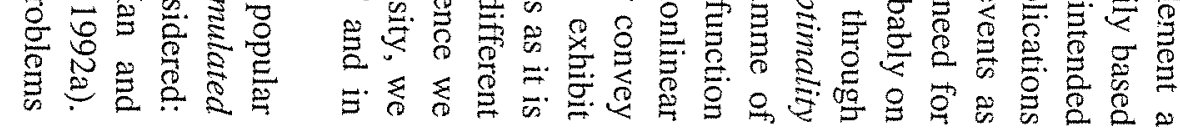

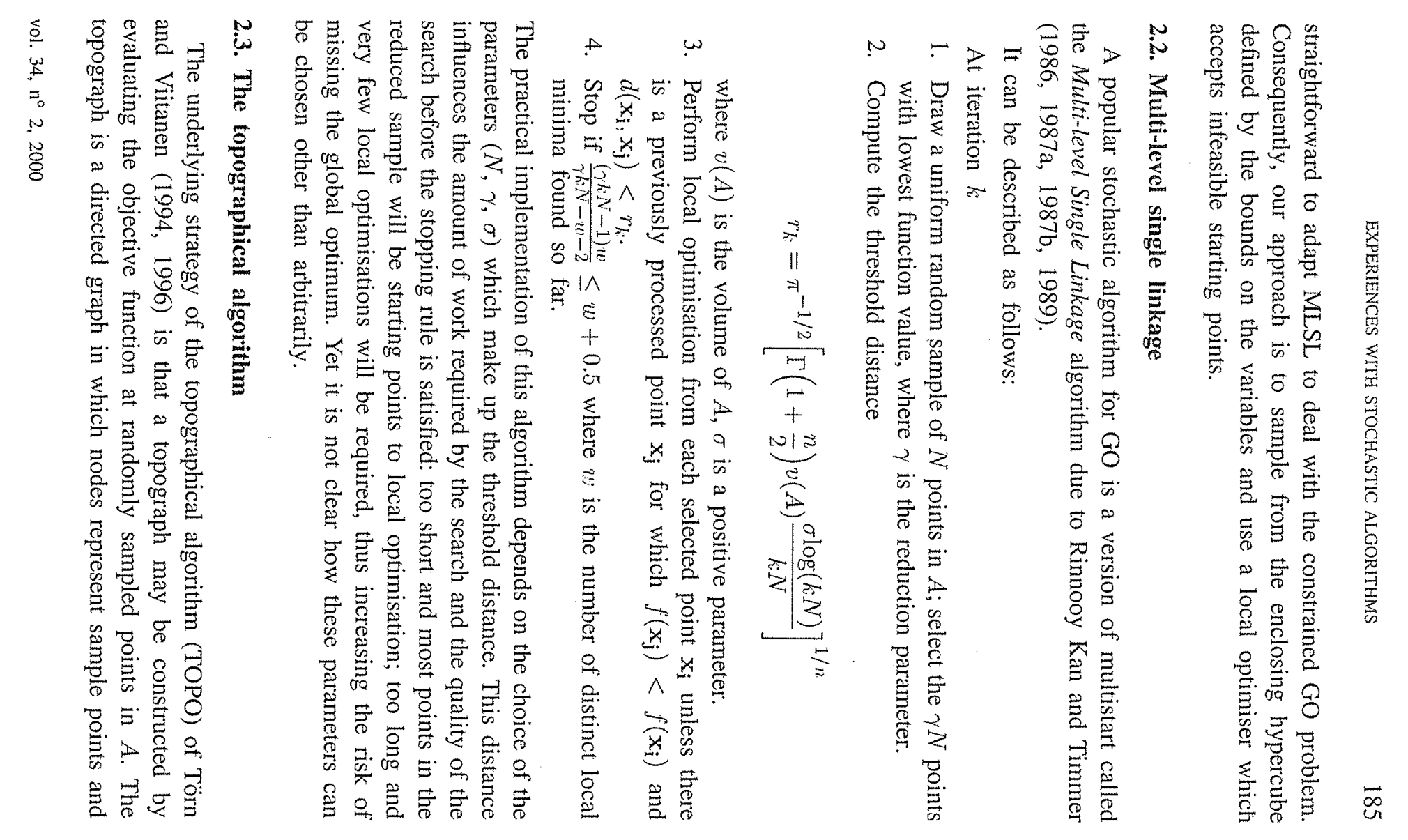




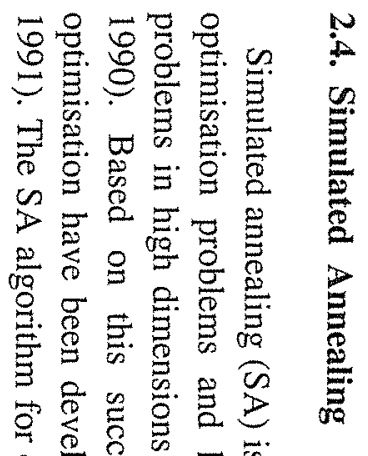

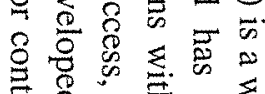
年

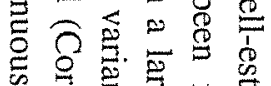
की

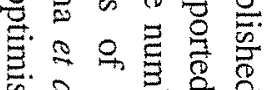

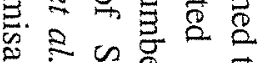

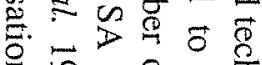

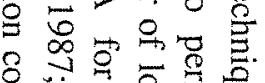

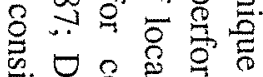

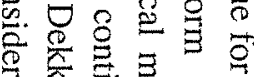

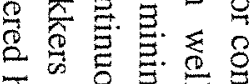
하을 क्ष

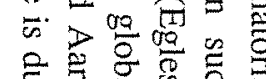

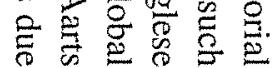

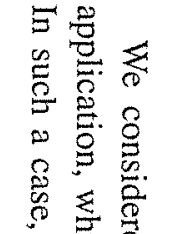

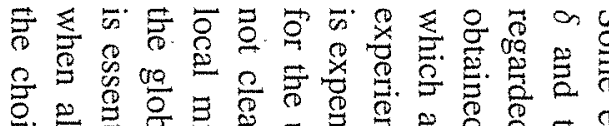

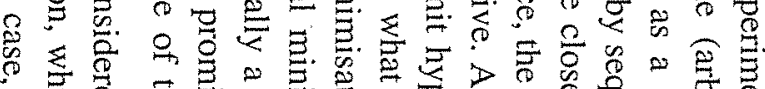

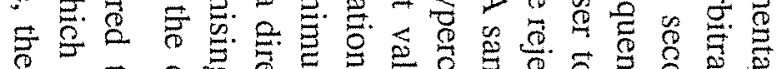

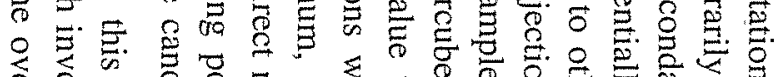

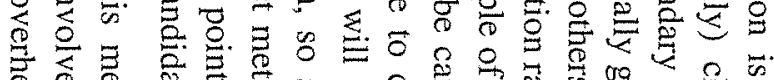

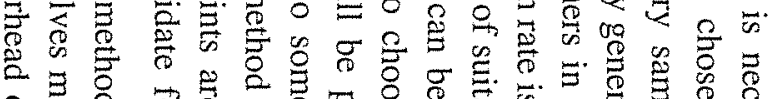

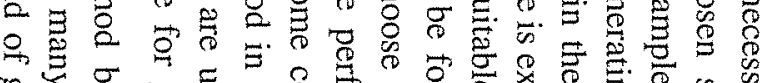

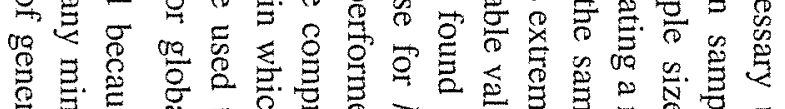

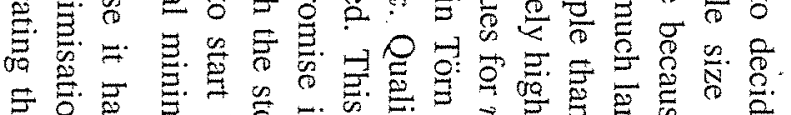

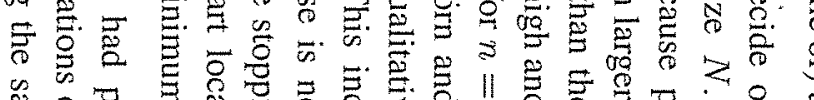

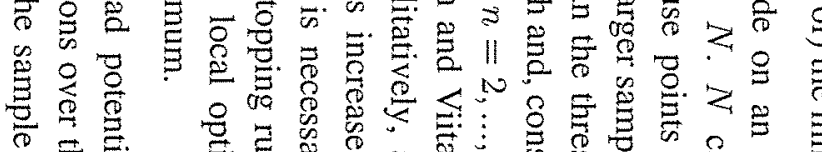

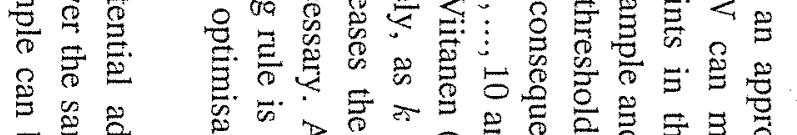

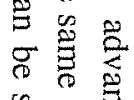

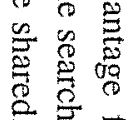

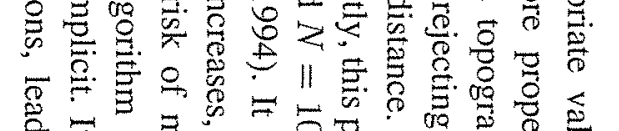

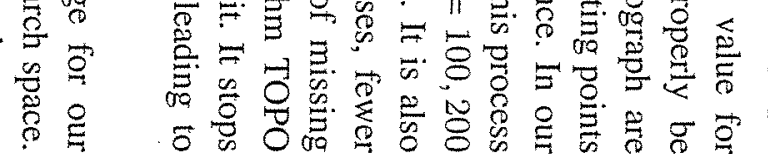

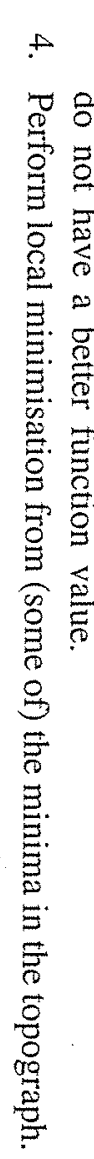

is

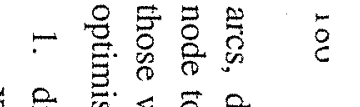

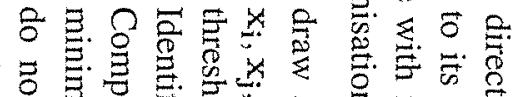

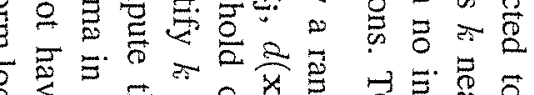

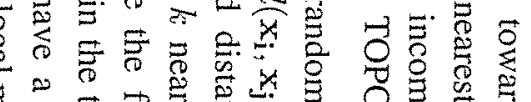

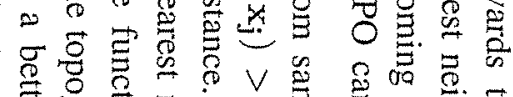

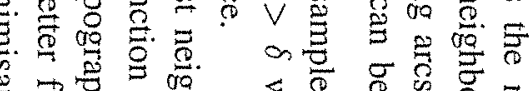

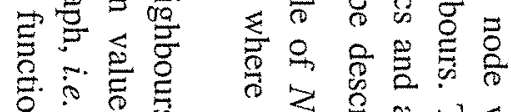

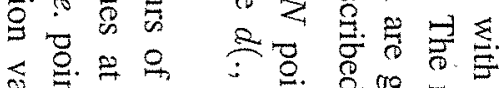

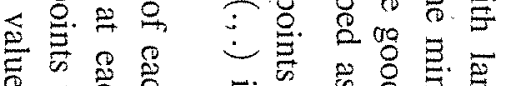
कृ

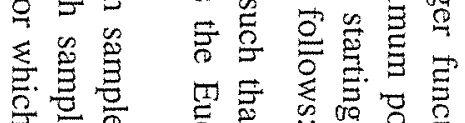

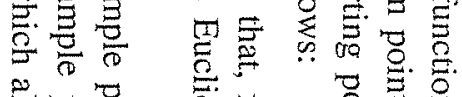

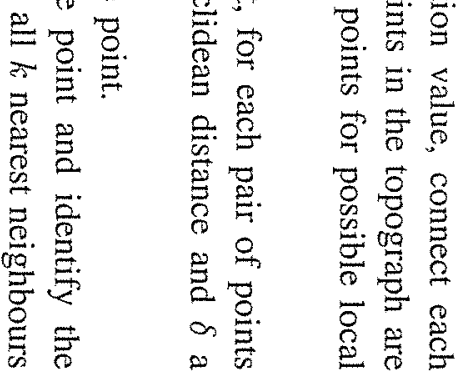

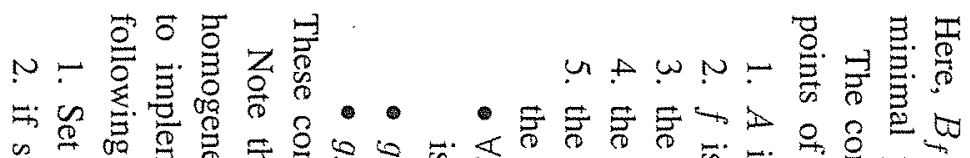

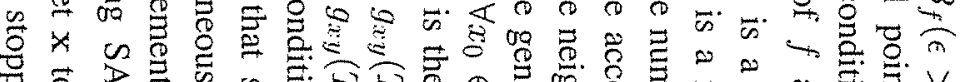

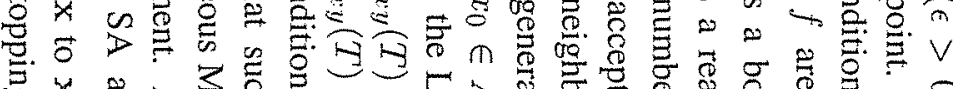

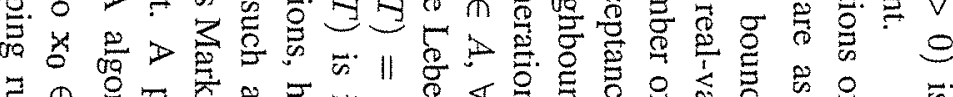

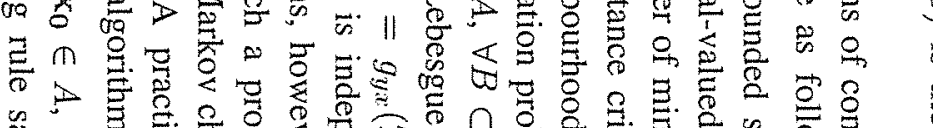

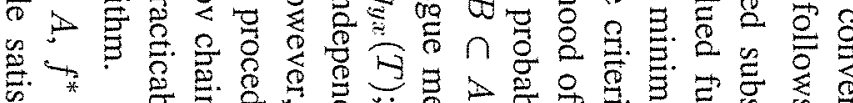

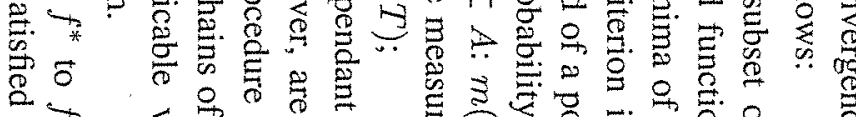

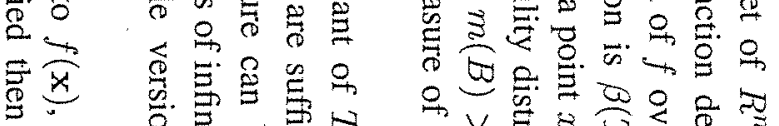

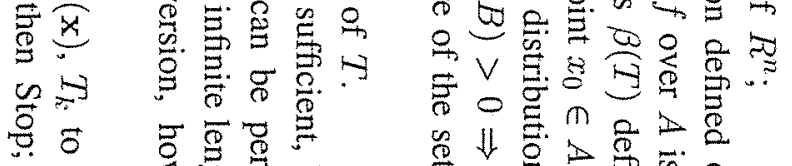

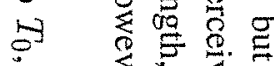

ㄴ.

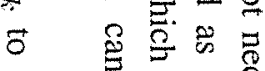

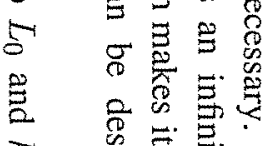

त

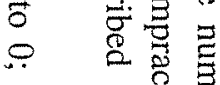

क

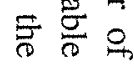

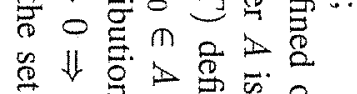

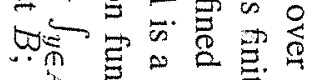

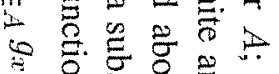

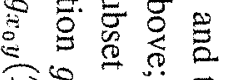

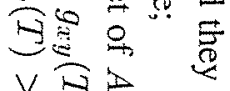

ज्ञा क्ष

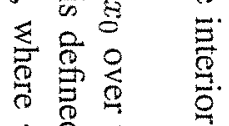

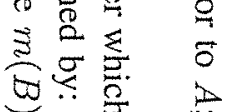

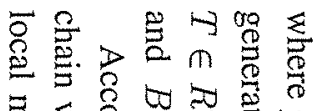

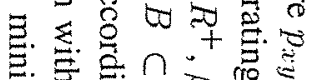

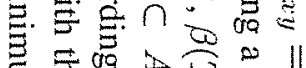

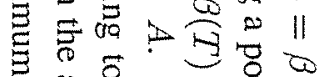

\&

영 余

↔

め) 葛.

$\cap$ 독

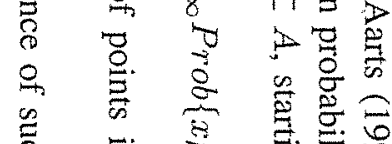

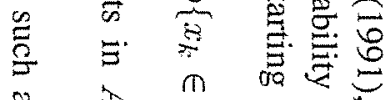

0

ठ융

造造

马. 艼苗.

马.

9 ज完

离范

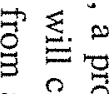

$\approx 8$

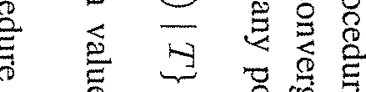

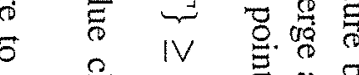

官总

पृ

क $\overline{0}$

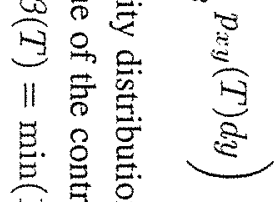

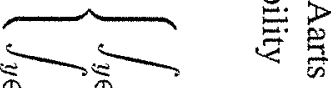

$\infty \infty_{\infty}^{\infty}$

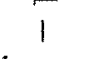

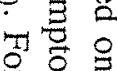

产

节.

觌 宇

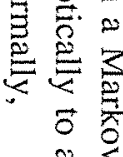

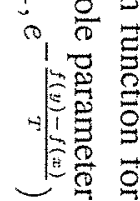

$\overbrace{\frac{3}{3}}^{\frac{8}{3}}$

$+$

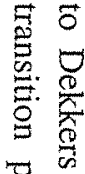

总若

䓛点

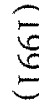

$F$

क

言

की

疍

$\stackrel{8}{g}$

$\vec{B} \quad \vec{\theta}$

$\infty \quad \infty$ 


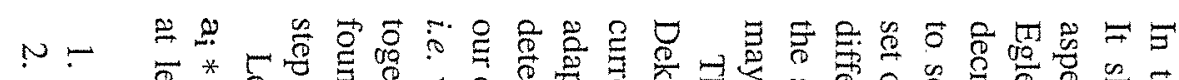

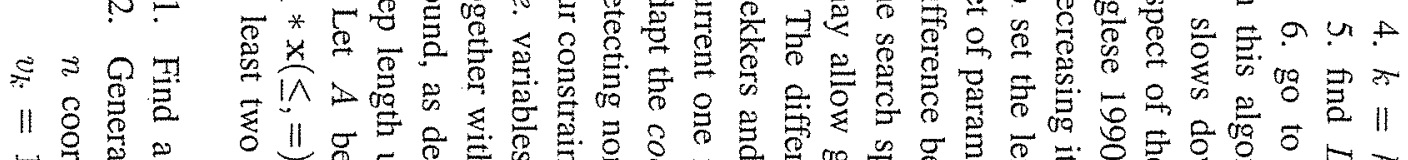

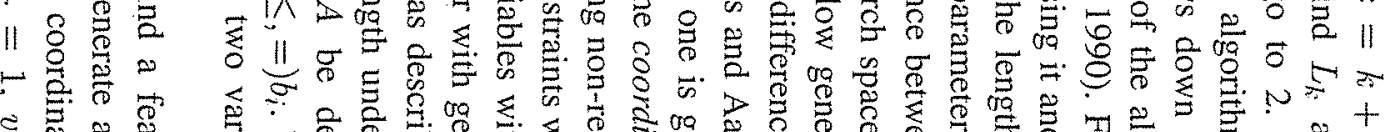

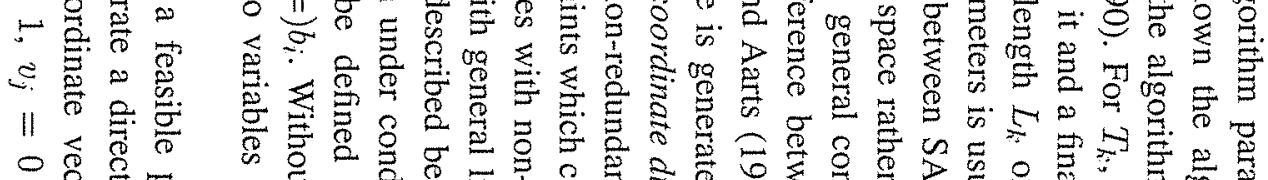

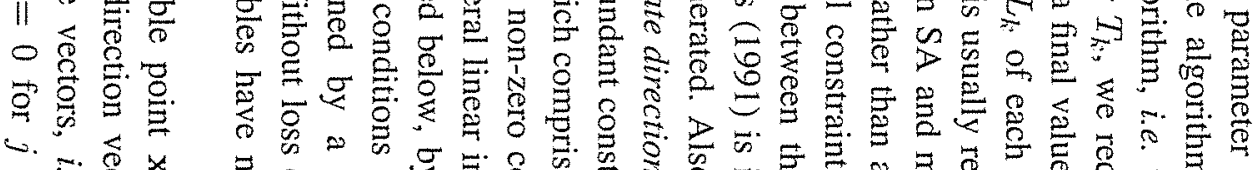
w

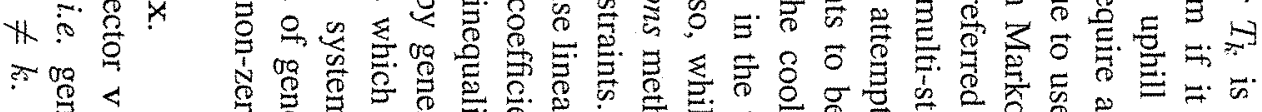

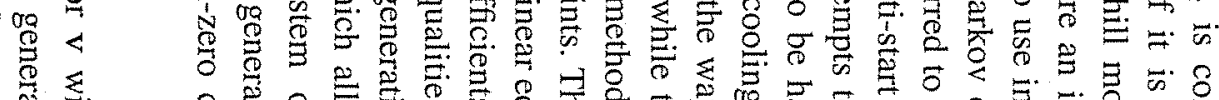

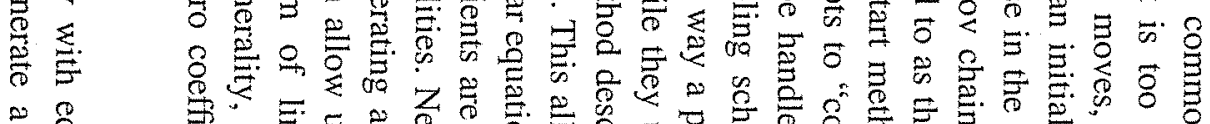

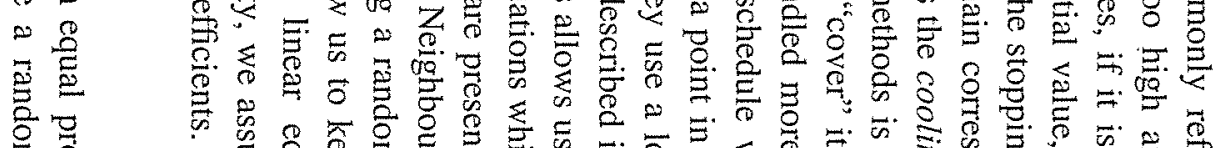

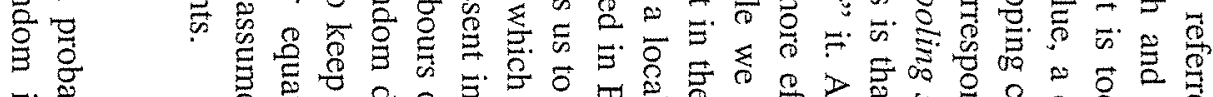

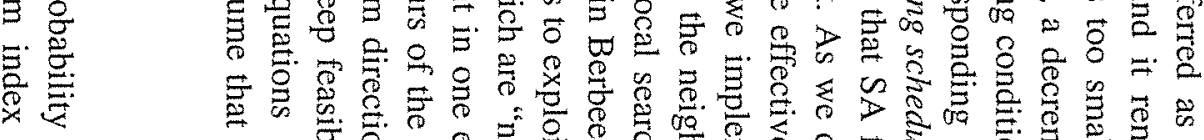

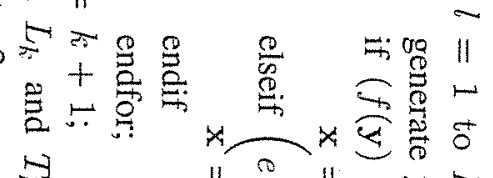

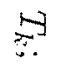

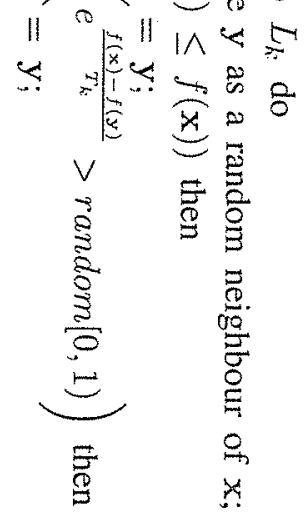

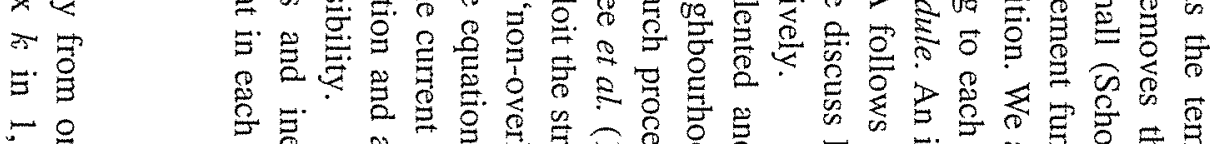

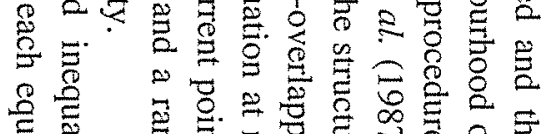

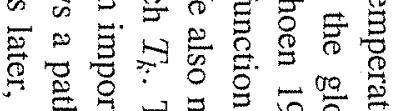
通宽

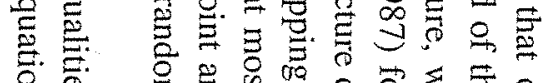

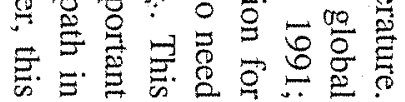

$\frac{1}{2}$

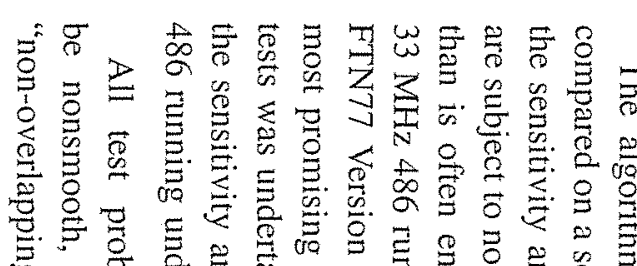

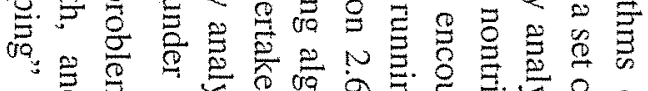

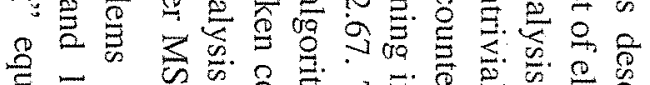

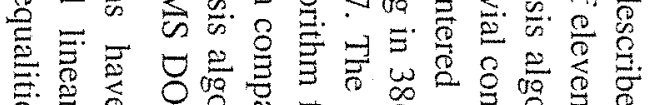

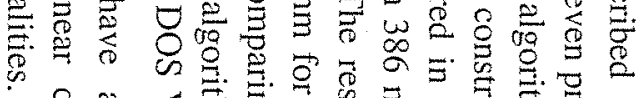

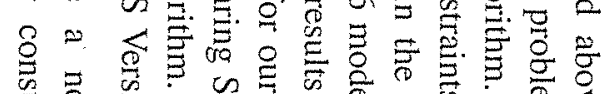

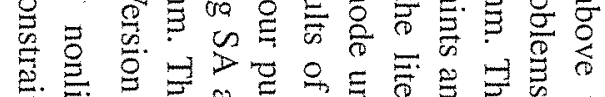

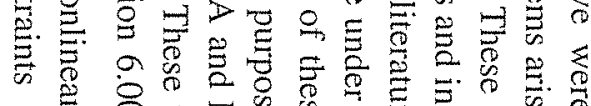

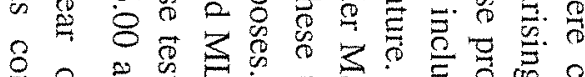

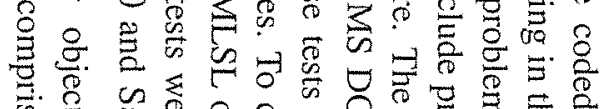

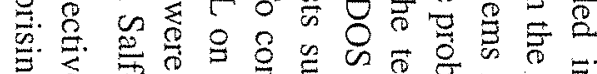

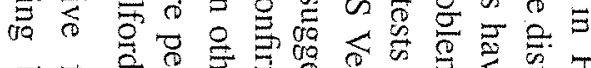

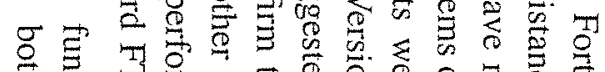

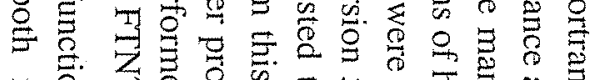

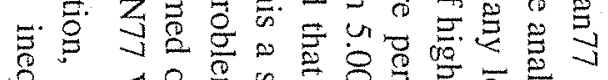

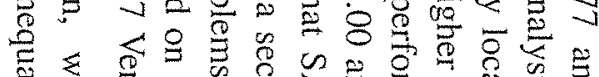

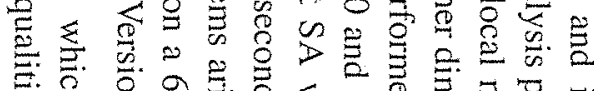

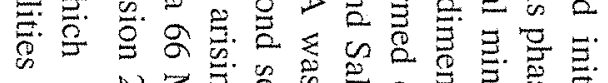

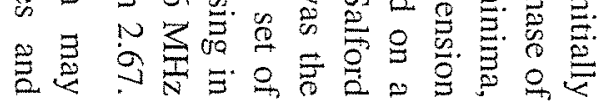

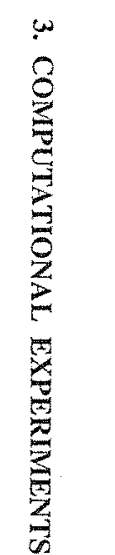

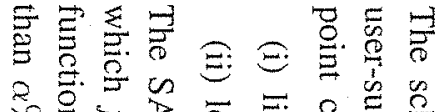

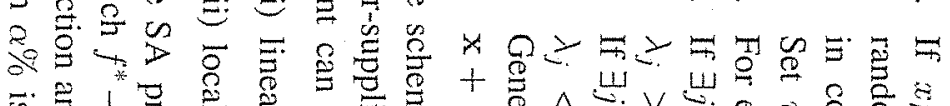

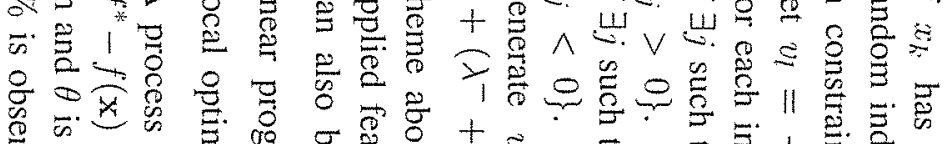

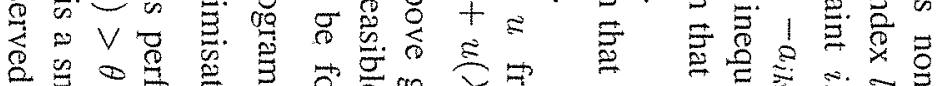

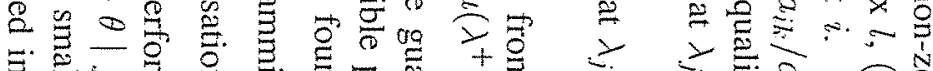

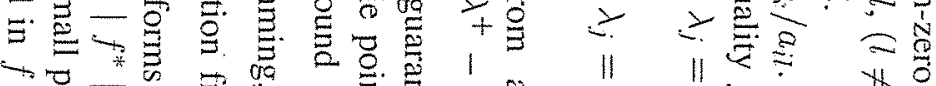

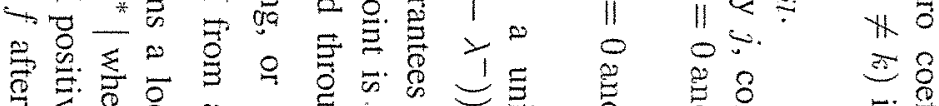

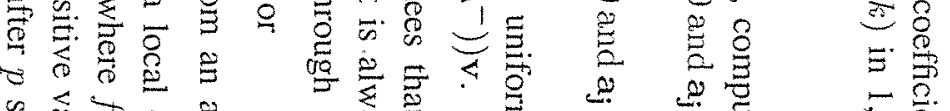

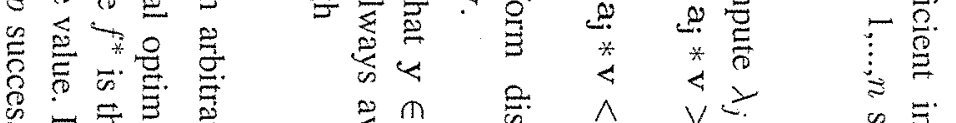

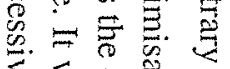

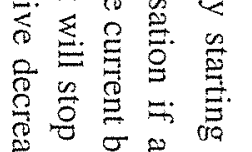

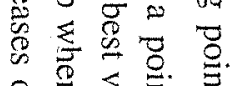

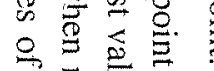

ब $\bar{\sigma} \bar{\sigma}$

当용.

产夏

용 융

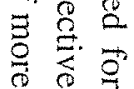

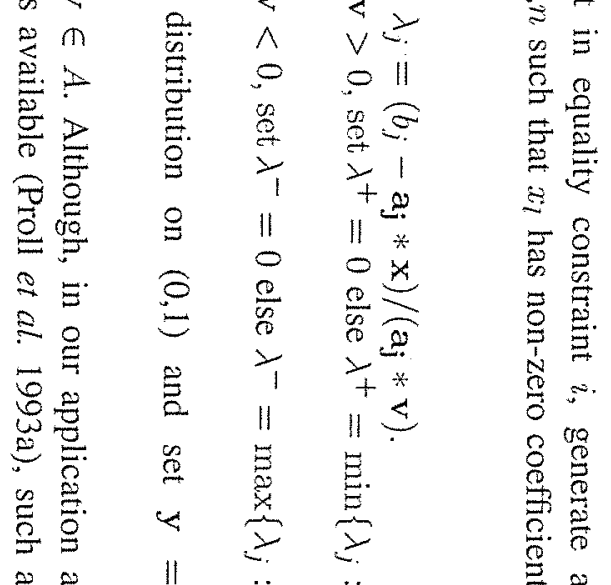




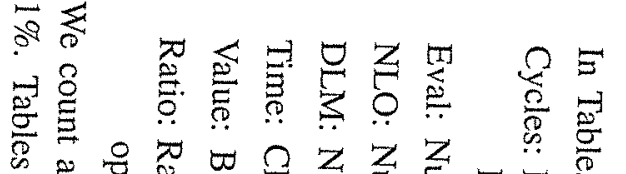

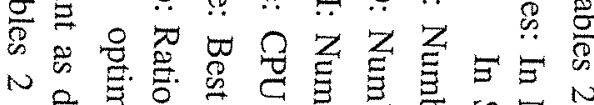

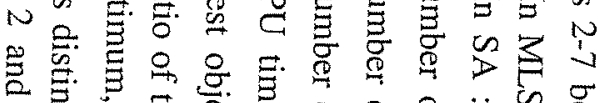

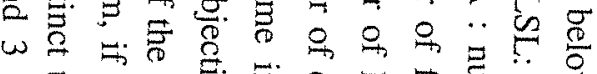

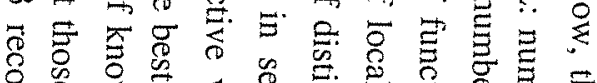

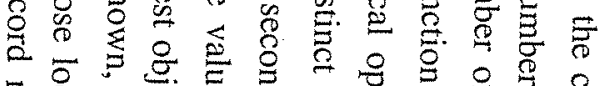

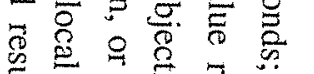
훙하

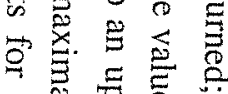
实要

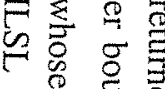
政言 ㅊ: 뜰 罢敦言

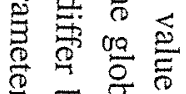

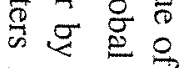

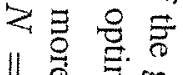

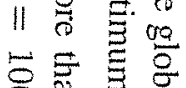

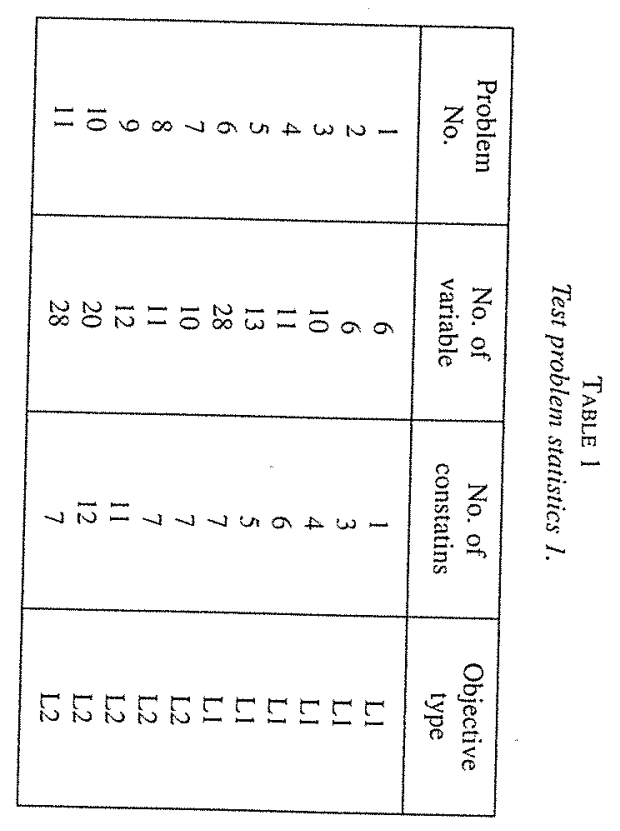

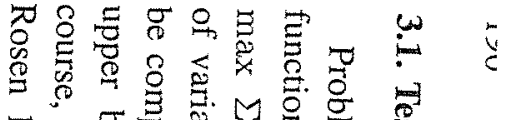

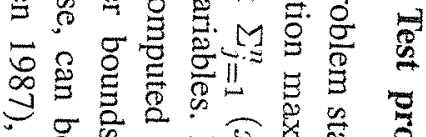

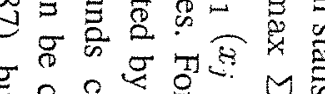

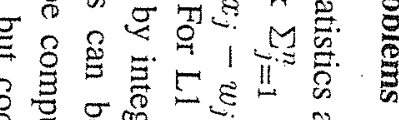

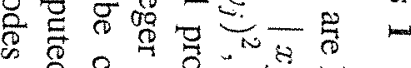

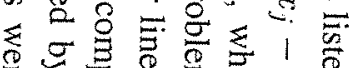

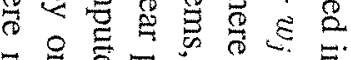

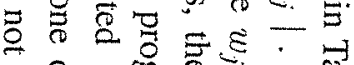

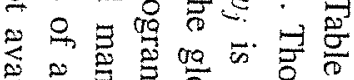

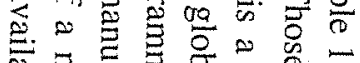

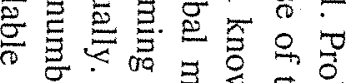

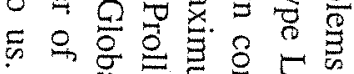

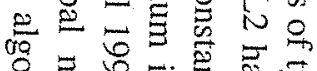

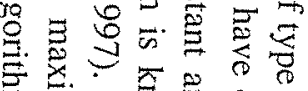

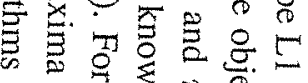

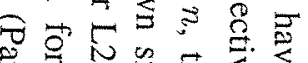

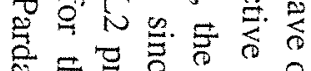

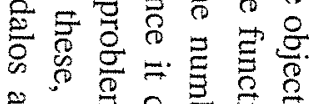

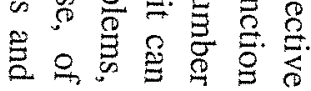

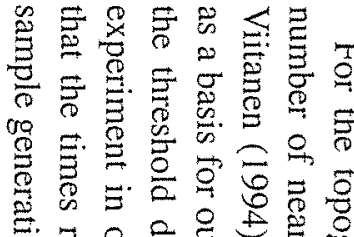

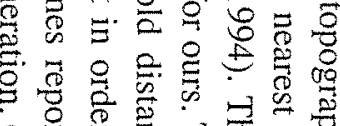

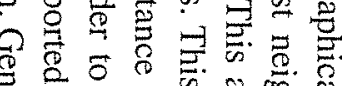

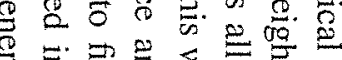

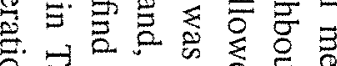

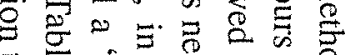

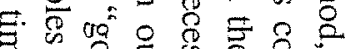

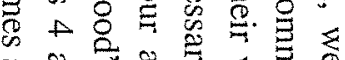

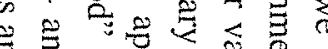

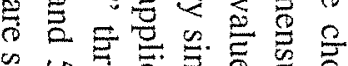

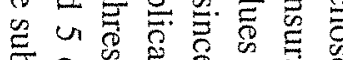

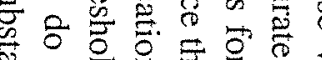

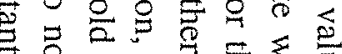

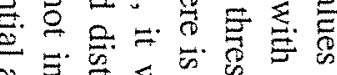

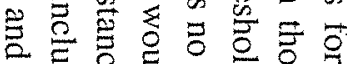

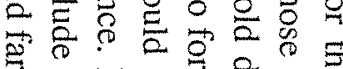

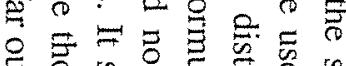

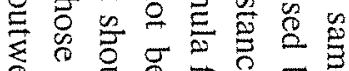
유 过 0 क 邑 宁

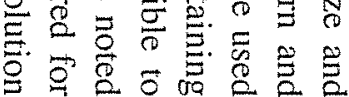

\begin{tabular}{|c|c|}
\hline$=\overline{0} 0 \infty \nu a u \neq \omega N-$ & $\frac{\vec{\sigma}}{\frac{\sigma}{9}}$ \\
\hline 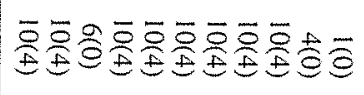 & $\stackrel{2}{\frac{2}{9}}$ \\
\hline 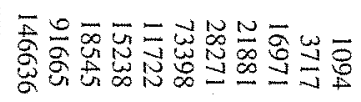 & $\stackrel{\text { T⿰冫 }}{\triangleq}$ \\
\hline 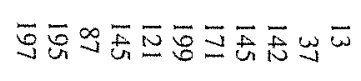 & $z$ \\
\hline 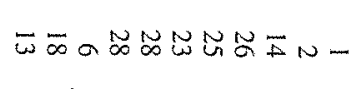 & $\stackrel{\vartheta}{?}$ \\
\hline 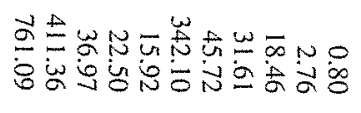 & 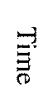 \\
\hline 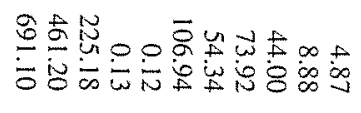 & 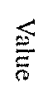 \\
\hline 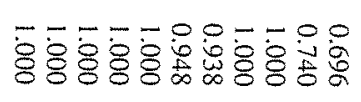 & 莺. \\
\hline
\end{tabular}

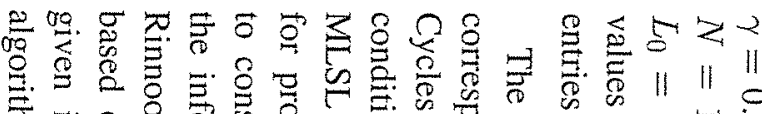
声

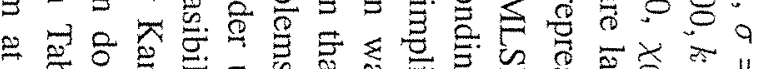

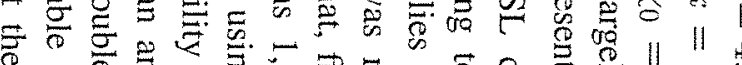

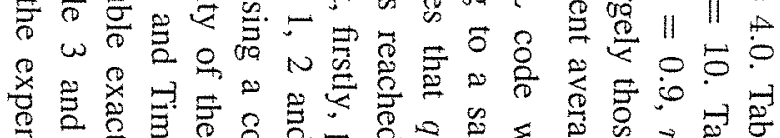

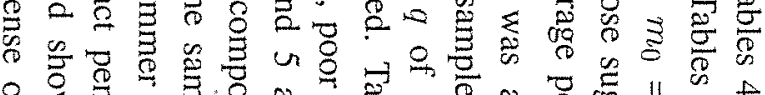

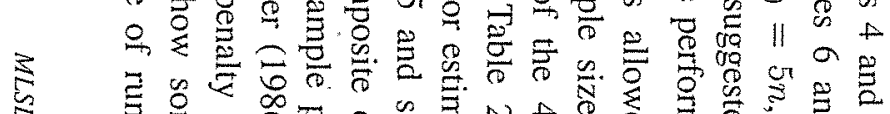

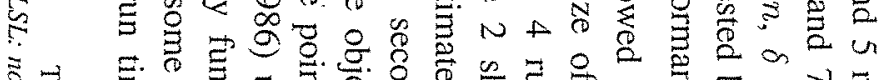

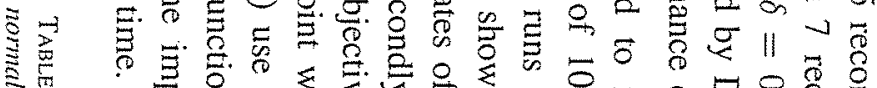

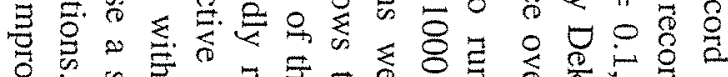
○

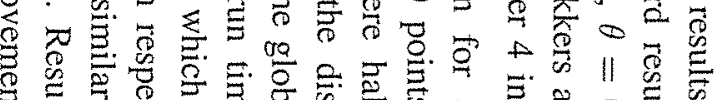

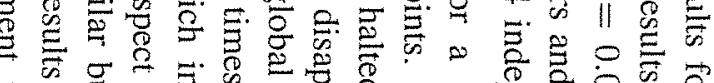

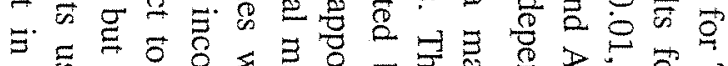

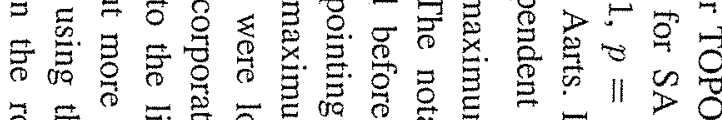

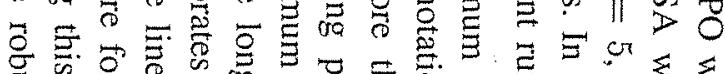

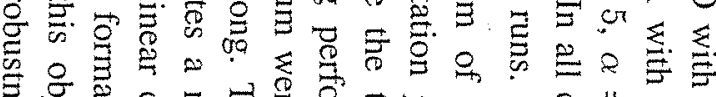

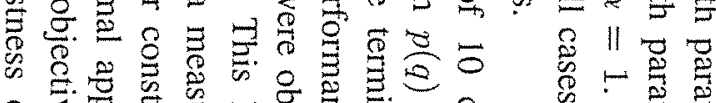

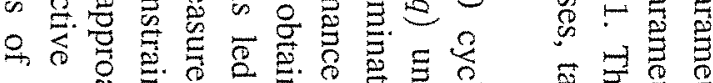

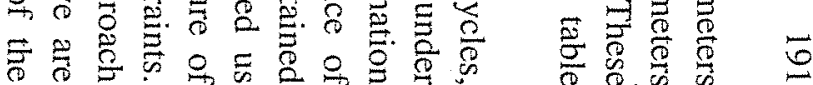




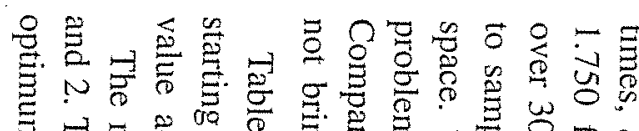

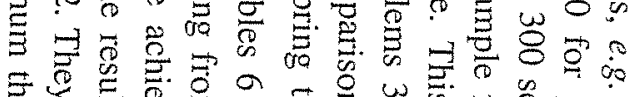
F

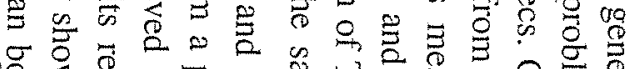
䒬

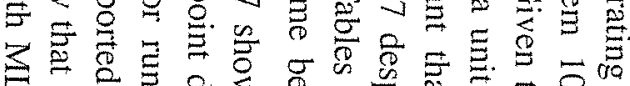

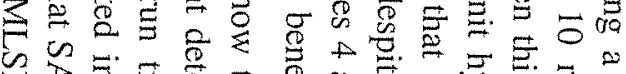

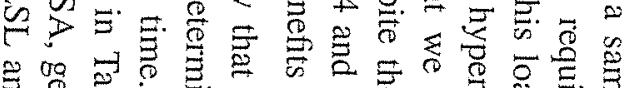

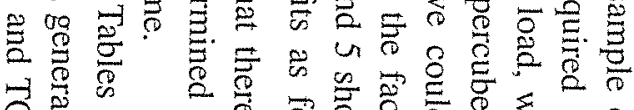
员运 氨言

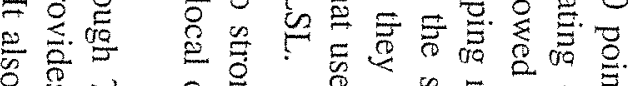

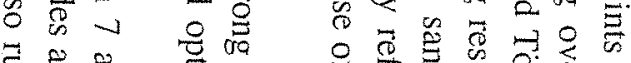

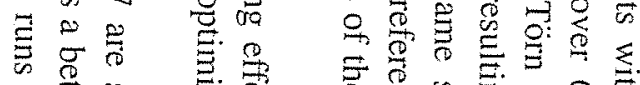

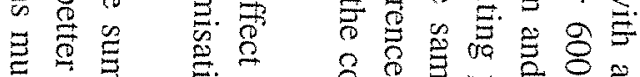
훙

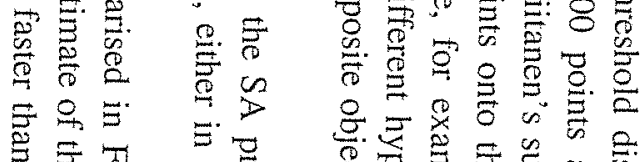

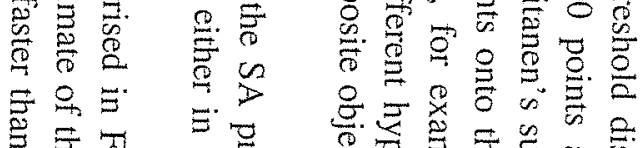

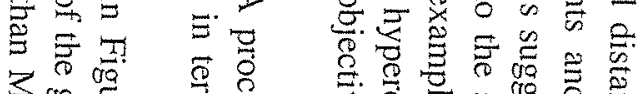

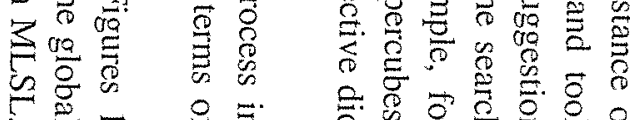

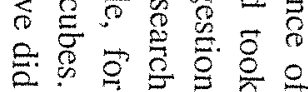

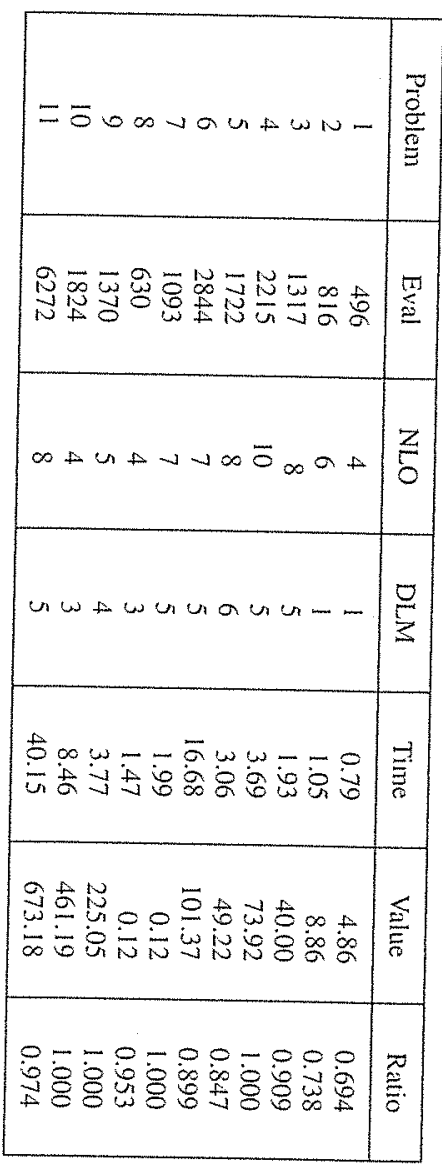

总

\begin{tabular}{|c|c|}
\hline$=\overline{0} 00 v a u+w n-$ & $\frac{\sqrt{3}}{\frac{9}{3}}$ \\
\hline 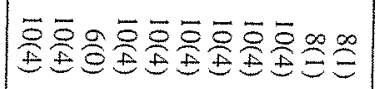 & $\frac{\Omega}{8}$ \\
\hline 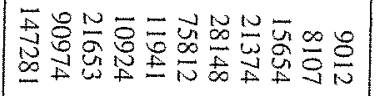 & 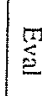 \\
\hline 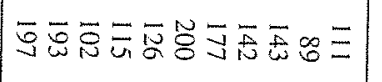 & $z$ \\
\hline 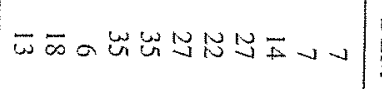 & $\frac{0}{3}$ \\
\hline 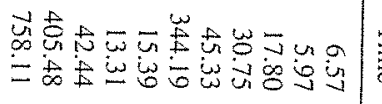 & 言 \\
\hline 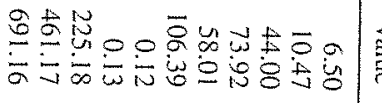 & 产 \\
\hline $5 \overline{8}$ & \\
\hline
\end{tabular}

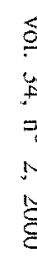

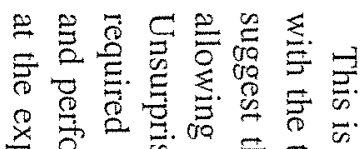

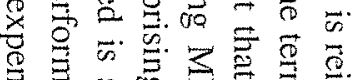

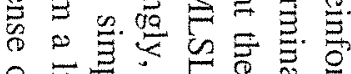

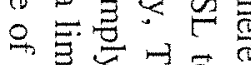

可苛

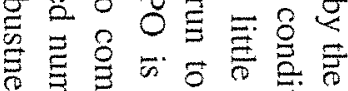

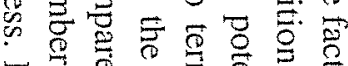

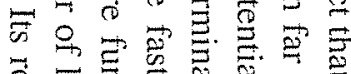

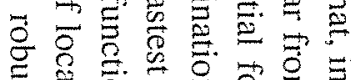

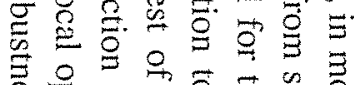

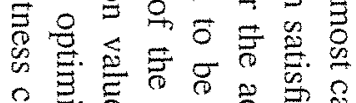

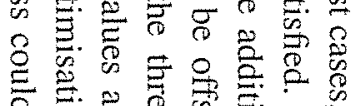

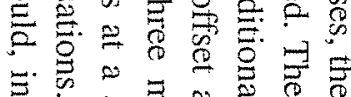

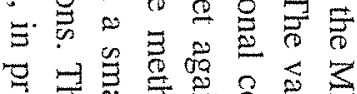

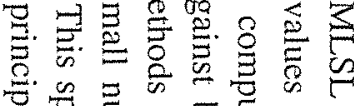

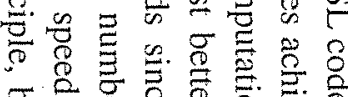

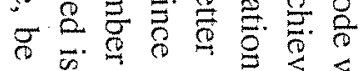

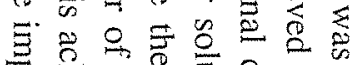
昰五.

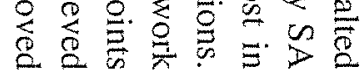

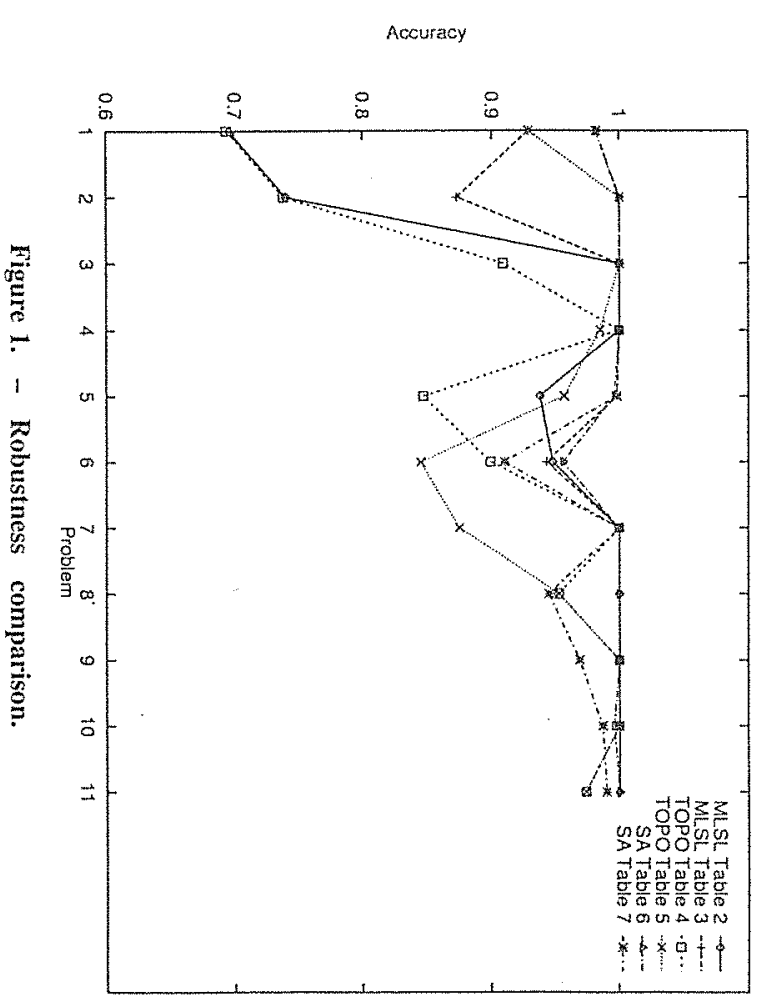

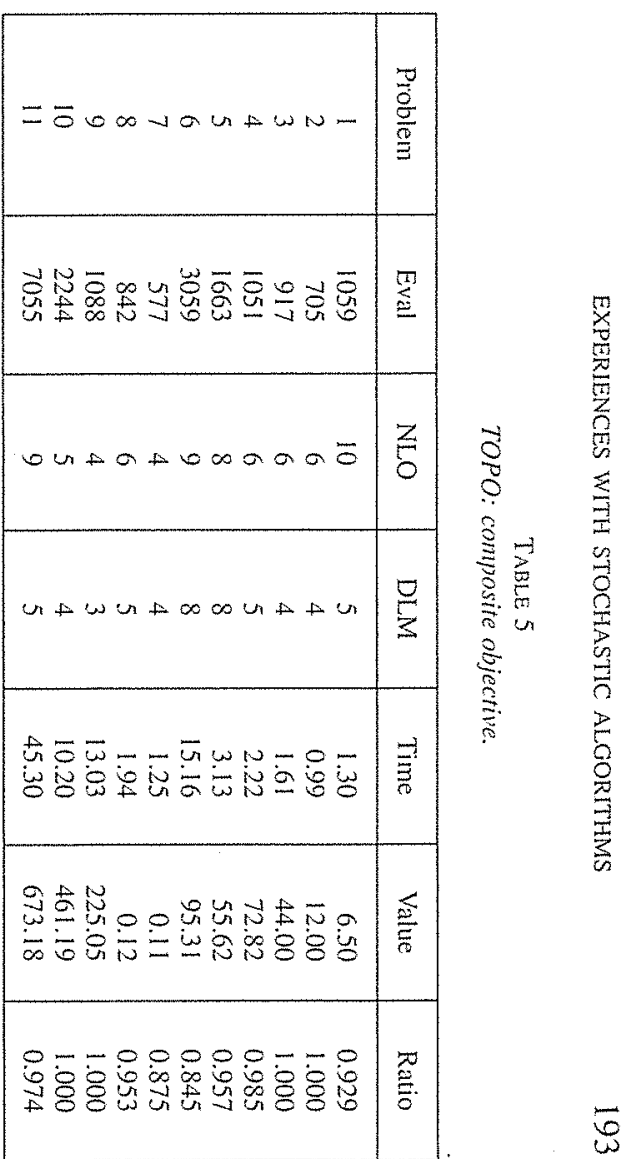




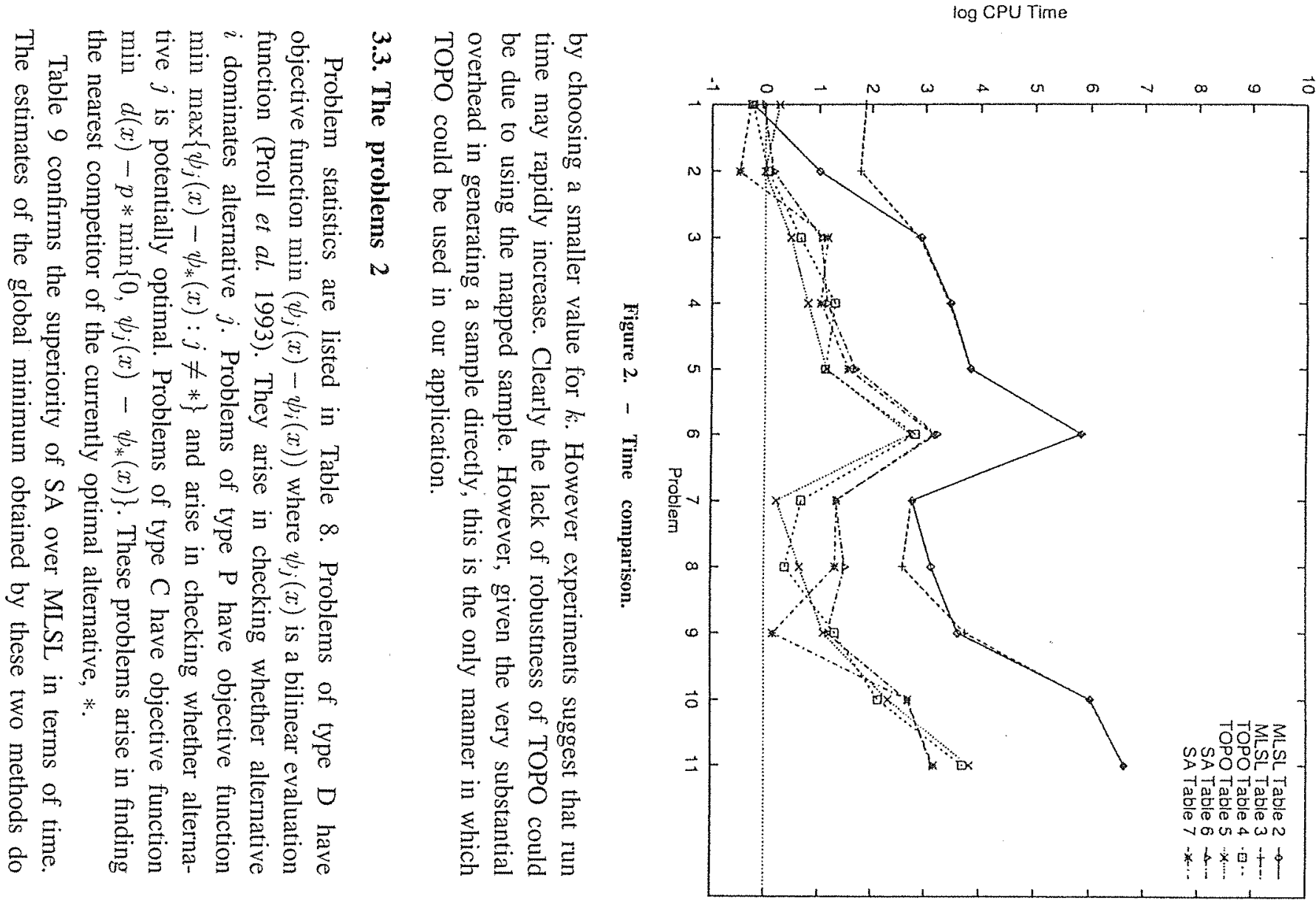

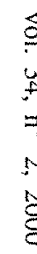
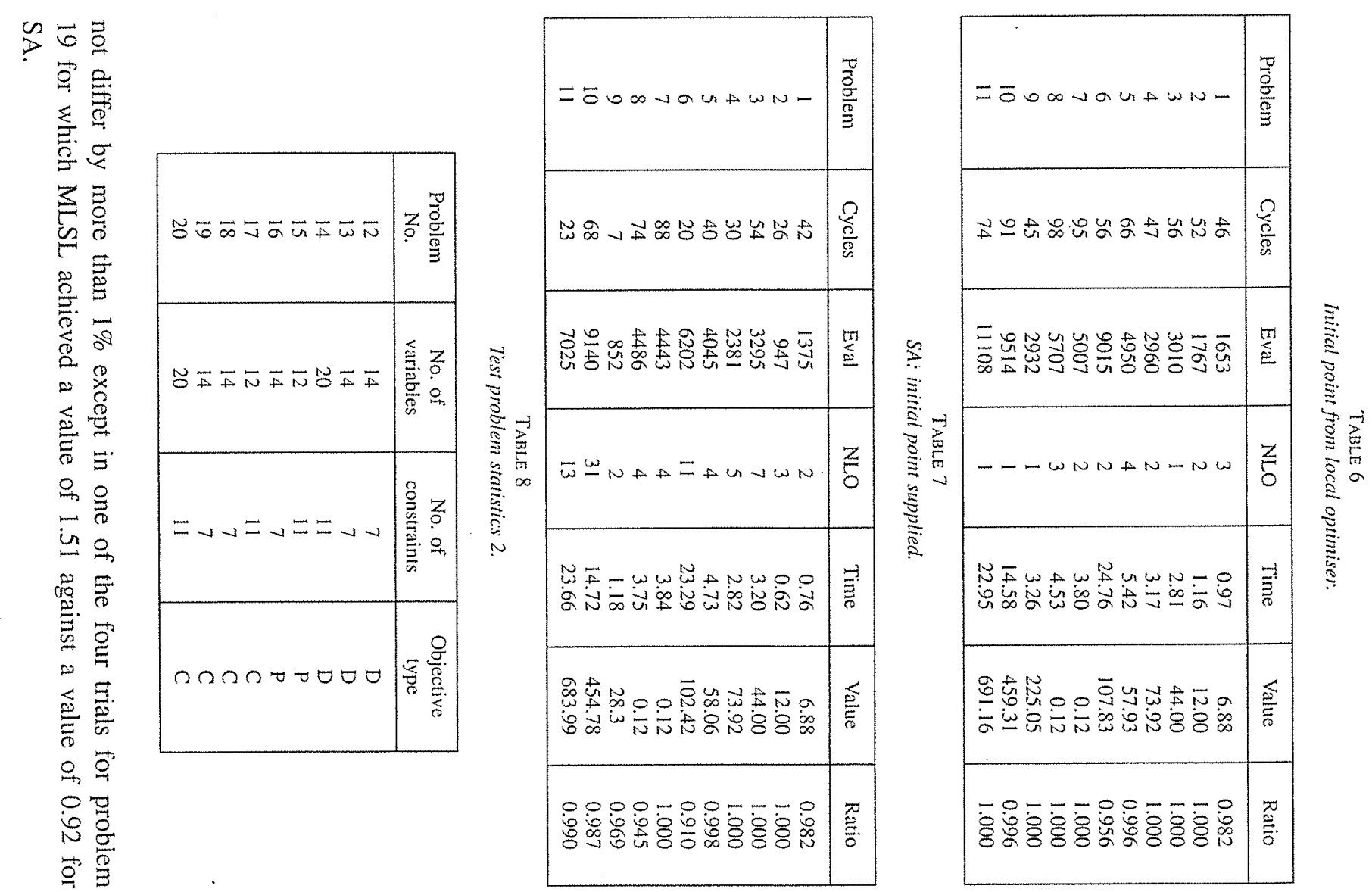


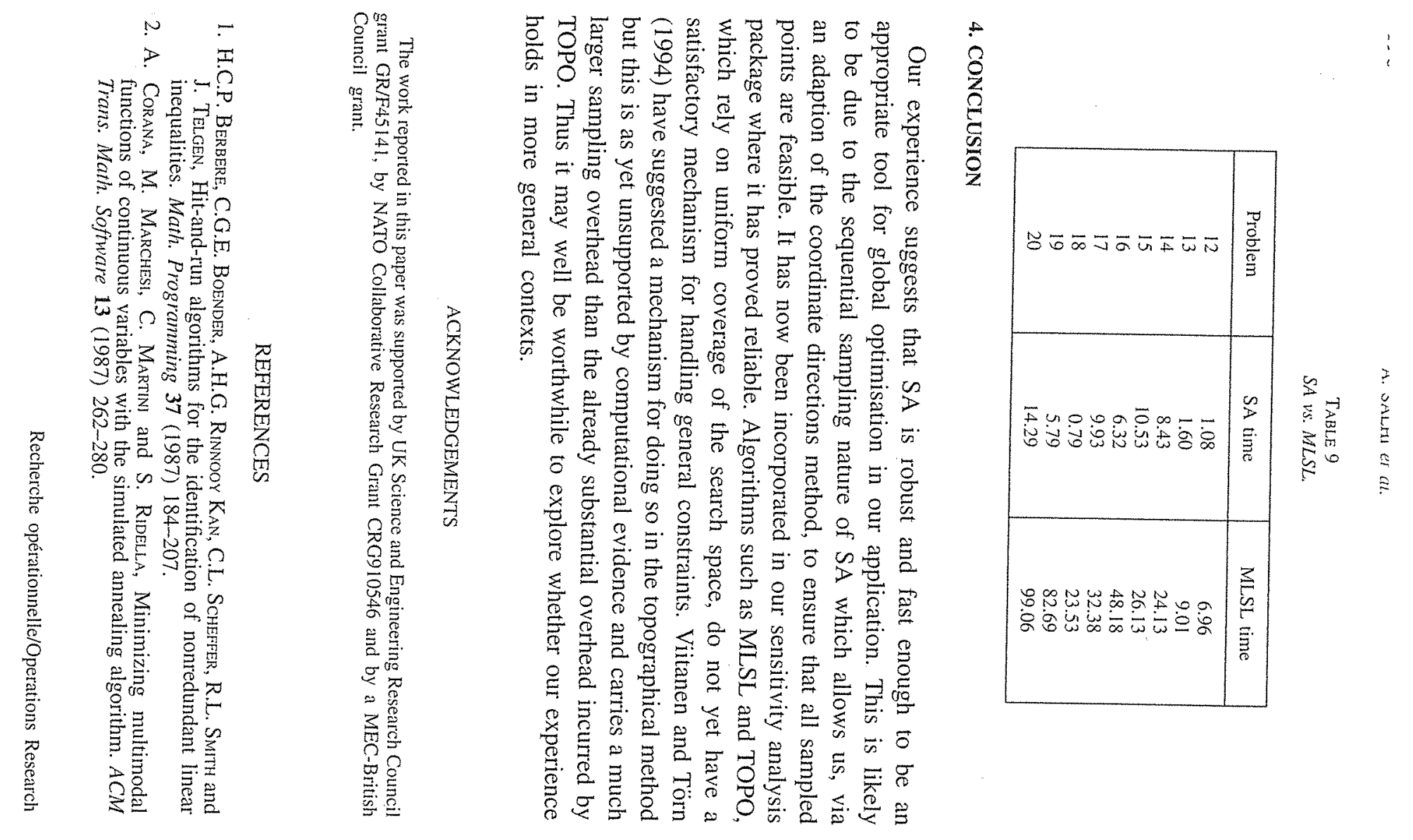

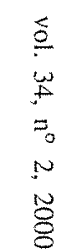

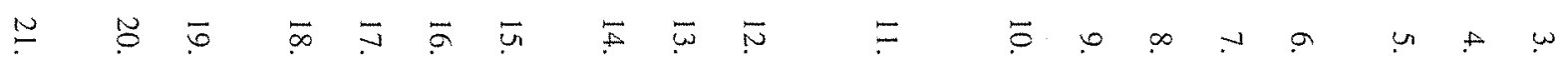

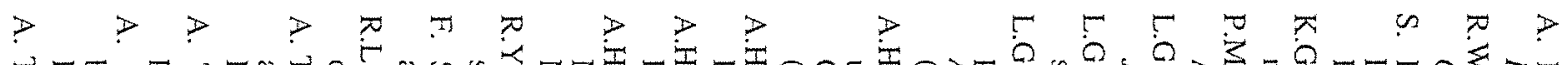

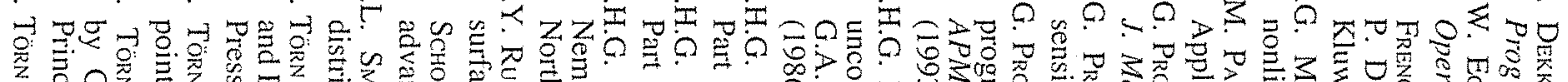

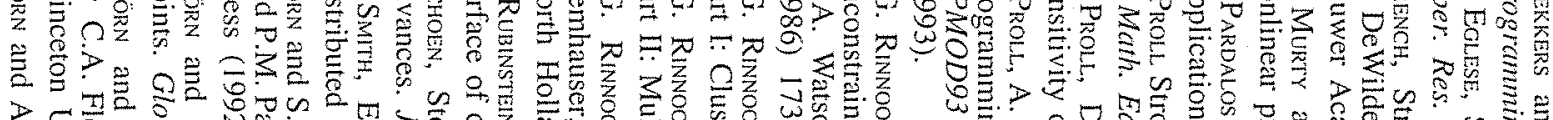

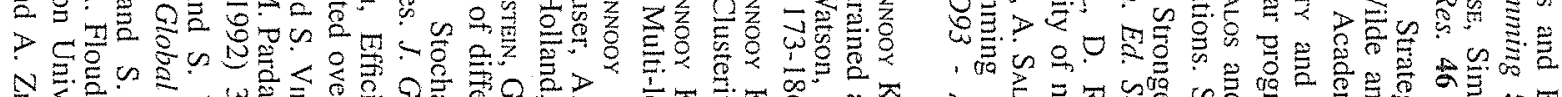

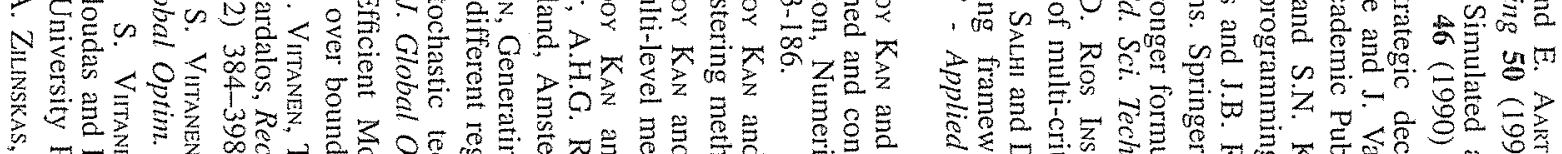

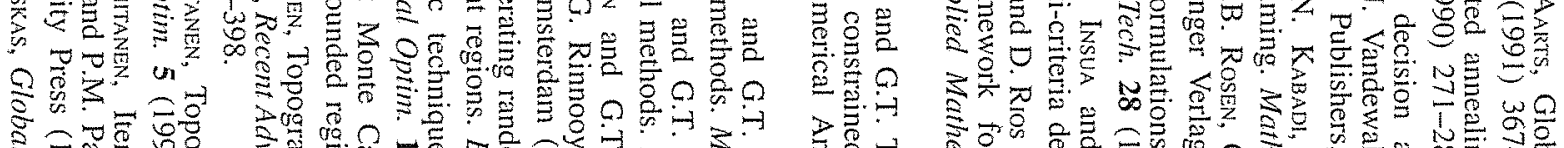

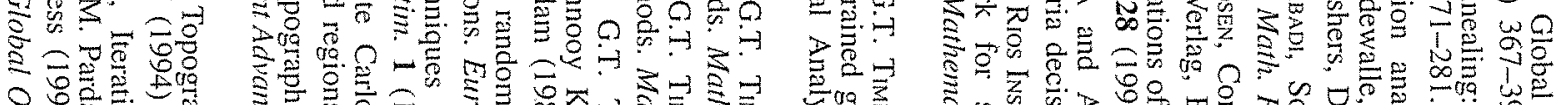

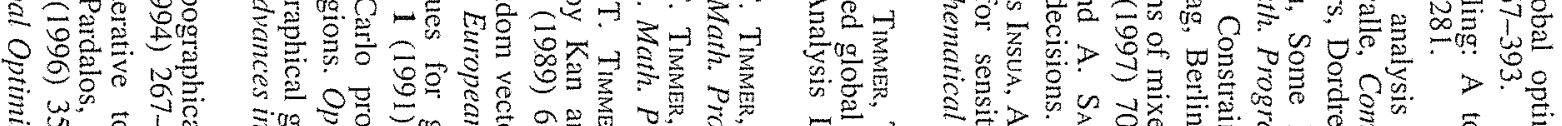

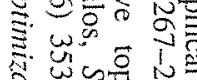

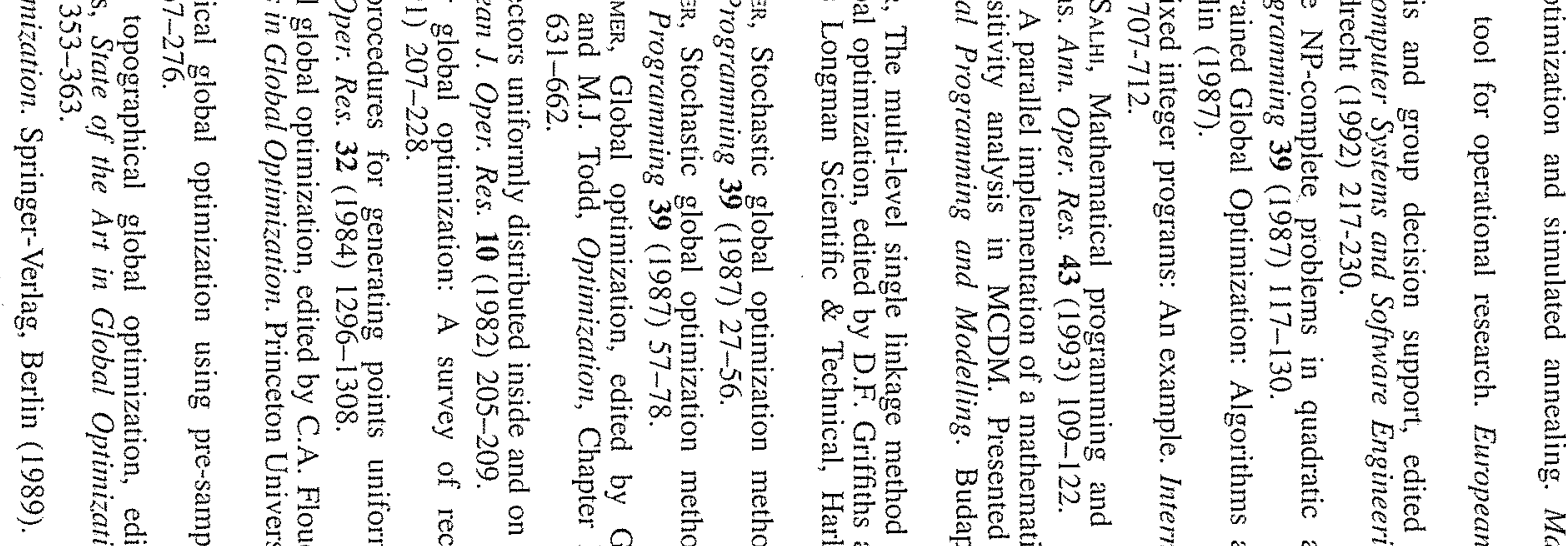

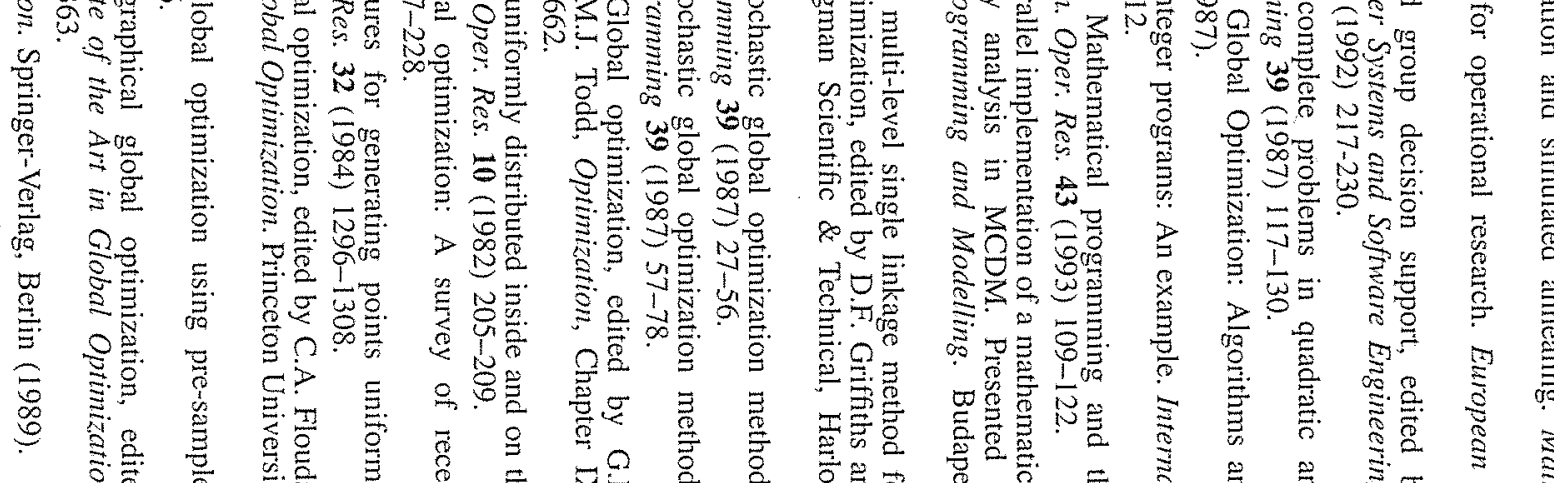

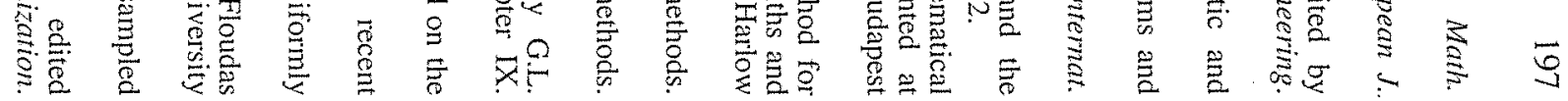

